\title{
Efektivitas Pendampingan Penyusunan Instrumen Penilaian Sikap bagi Guru SD
}

\author{
Mawardi ${ }^{1}$, Agustina Tyas Asri Hardini ${ }^{2}$ \\ 1, 2 Universitas Kristen Satya Wacana, Indonesia
}

\begin{abstract}
A B S T R A C T
EFFECTIVENESS OF MENTORING INSTRUMENT PREPARATION OF ATTITUDE ASSESSMENT FOR ELEMENTARY SCHOOL TEACHERS. The purpose of devotion to society in the form of this training is to increase the competence of elementary school teachers in THE KKG Group of Dr. Wahidin Soediro Hoesodo District, Central Java in order to develop a scale instrument of attitude. The benefits gained by the participants in this training and mentoring are the increasing understanding and experience for the teacher in organizing the instrument of attitude. This activity is implemented by the following steps: 1) Identifying the ability of the trainees, 2) sets the need Gap, 3) develops the program, 4) conducting the training, and 5) evaluation. Based on the findings of the training as described above, the following steps included : 1) The training on the preparation of attitude assessment instruments is an urgent necessity; 2) The average Pretest score in training only reaches 54; While on final test reached 69.76. A minimum score pretest 23 and final test 47; Maximum score pretest 72 and final test 79 . The increase in the achievement of the learning outcomes is quite meaningful, both seen from the average and from the achievement of the maximum score of 79;3) found data from 25 elementary school teachers who attended the training, 16 of them $(68 \%)$ has uploaded training products in the form of Likert model scale instrument. Compared to the specified PM target of $60 \%$, this achievement has exceeded the target.
\end{abstract}

Keywords: Attitude Instrument, Blended Learning.

\begin{tabular}{llll}
\hline Received: & Revised: & Accepted: & Available online: \\
19.03.2020 & 02.07 .2020 & 22.10 .2020 & 30.11 .2020 \\
\hline
\end{tabular}

\section{Suggested citation:}

Mawardi, \& Hardini, A. (2020). Efektivitas pendampingan penyusunan instrumen penilaian sikap bagi guru SD. Jurnal Pengabdian Pada Masyarakat, 5(4), 974-982. https://doi.org/10.30653/002.202054.466

Open Access I URL: http://ppm.ejournal.id/index.php/pengabdian/article/view/466

\footnotetext{
${ }_{1}$ Corresponding Author: Program Studi Pendidikan Guru Sekolah Dasar, FKIP Universitas Kristen Satya Wacana; Jl. Diponegoro 52-60 Salatiga, Indonesia. Email: mawardi@uksw.edu
} 


\section{PENDAHULUAN}

Guru SD di samping melakukan kewajibannya sebagai pengajar juga harus melakukan penilaian pembelajaran. Penilaian dilakukan dengan tahapan awal memahami hakikat dan penilaian, memahami cakupan ranah atau aspek yang dinilai, merancang prosedur penilaian, menyusun instrumen, melaksanakan penilaian, mengadministrasikan hasilnya, mengolah hasil, melaporkan hasil dan menggunakan hasil penilaian untuk melakukan pembinaan siswa dan memperbaiki pembelajaran. Salah satu kegiatan merancang penilaian yang penting adalah merancang penilaian untuk ranah sikap (afektif), dibandingkan dengan penilaian ranah pengetahuan (kognitif) maupun ranah keterampilan (psikomotorik) yang telah dilakukan secara rutin. Penilaian ranah sikap merupakan obyek penilaian yang abstrak, maka diperlukan pemahaman dan keterampilan yang cukup baik untuk melaksanakannya. Berkaitan dengan itu maka PKG guru SD Gugus Dr. Wahidin Soediro Hoesodo-Batang melakukan kegiatan pelatihan dan pendampingan untuk meningkatkan kemampuan guru dalam menyusun instrumen penilaian ranah sikap. Melalui kegiatan pelatihan ini diharapkan kemampuan guru-guru dalam menyusun instrumen penilaian ranah afektif meningkat.

Istilah penilaian pembelajaran merupakan suatu kegiatan guru selama rentang pembelajaran yang berkaitan dengan pengambilan keputusan tentang pencapaian kompetensi peserta didik yang memiliki karakteristik individual yang unik (BalitbangDepdiknas, 2006). Dalam rangka pengambilan keputusan tersebut, diperlukan data sebagai informasi yang diandalkan sebagai dasar pengambilan keputusan. Data yang diperoleh guru selama pembelajaran berlangsung dijaring dan dikumpulkan melalui prosedur dan alat penilaian yang sesuai dengan kompetensi atau indikator yang akan dinilai. Dari proses ini, diperoleh potret/profil kemampuan peserta didik dalam mencapai sejumlah standar kompetensi dan kompetensi dasar yang dirumuskan dalam Kurikulum 13.

Sebagaimana diketahui bahwa dalam Kurikulum 2013, ada empat Kompetensi Inti (KI) yang harus dinilai, yaitu KI-1 sikap religius, KI-2 sikap sosial, KI-3 tentang kompetensi pengetahuan dan KI-4 tentang kompetensi ketarampilan. Berkaitan dengan pengalaman melaksanaakan penilaian ke-empat kompetensi ini, para guru SD menyatakan bahwa praktik penilaian kompetensi KI-1 dan KI-2 yang berkaitan dengan ranah afektif masih belum memadai, dibandingkan dengan praktik penilaian untuk KI3 dan KI-4. Para guru belum terlatih menyusun instrumen penilaian ranah afektif. Oleh karena itu upaya meningkatkan kompetensi guru dalam menyusun instrumen ranah afektif/sikap perlu dilakukan. Upaya yang dipandang tepat untuk meningkatkan kompetensi guru ini adalah dengan melakukan pelatihan.

Mengacu pendapat Noe, Hollenbeck, Gerhart, dan Wright (2010, p. 351), pelatihan guru adalah upaya yang direncanakan untuk meningkatkan penguasaan kompetensi guru yaitu penguasaan pengetahuan, keterampilan dan sikap dalam melaksanakan tugas profesionalnya. Pelatihan bagi guru bertujuan agar guru: (1) mampu memperbaiki kinerjanya. Guru yang memiliki kinerja kurang atau tidak memuaskan dapat disebabkan kurangnya pengetahuan, keterampilan dan sikap terhadap bidang pekerjaannya; (2) dapat memuthakhirkan keahliannya sejalan dengan kemajuan teknologi dan dapat menerapkannya dalam dalam pekerjaan sehari-hari; (3) membekali 
guru baru agar kompeten dalam pekerjaan, karena seringkali guru baru tidak menguasai keahlian dan kemampuan yang dibutuhkan dalam menjalankan tugastugasnya; (4) membantu memecahkan masalah yang dihadapi guru dalam menjalankan tugasnya, sehingga program pelatihan hendaknya dilandasi pada kebutuhan guru; (5) mengembangkan karier guru.

Langkah-langkah pelatihan menurut Pont (dalam Mudjiman, 2011) merupakan sebuah siklus kegiatan berkelanjutan yang terdiri dari: 1) analisis kebutuhan pelatihan, 2) perencanaan program pelatihan, 3) penyusunan bahan pelatihan, 4) pelaksanaan pelatihan, dan 5) penilaian pelatihan. Secara skematis siklus pelatihan tersebut dapat dilihat dalam gambar 1 berikut.

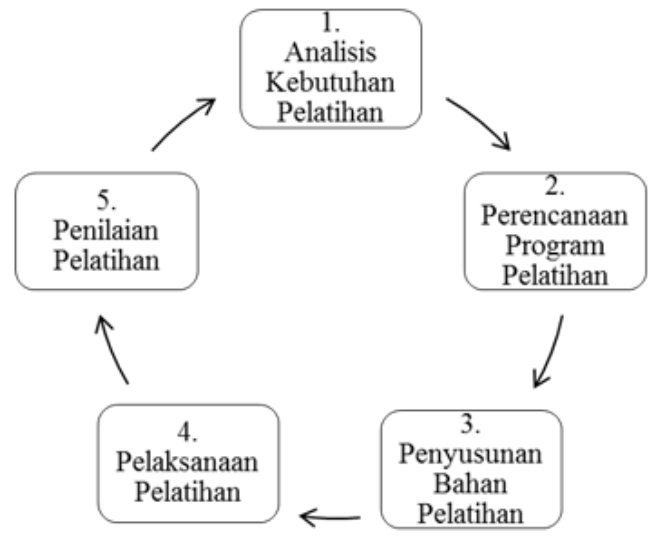

Gambar 1. Siklus pelatihan (Mudjiman, 2011)

Keinovasian dalam proyek perubahan ini adalah adanya kegiatan bimbingan teknik dengan menggunakan model Blended. Konsep pelatihan (training) menggunakan model blended sebenarnya diadaptasi dari model pembelajaran berbasis blended learning. Blended learning adalah pembelajaran yang menggabungkan dua sistem: yaitu sistem pembelajaran tatap muka yang bersifat klasikal (traditional learning) dan sistem pembelajaran yang menggunakan media computer/e-learning (Bonk \& Graham, 2012). Pembelajaran tatap muka dapat dilakukan dengan model presentasi, diskusi dan kerja kelompok, sementara sistem e-learning dapat berlangsung secara online melalui internet.Berdasarkan pengertian blended learning tersebut di atas, maka konsep ini dapat diterapkan dalam Bintek pelatihan penulisan dan publikasi karya ilmiah guru SD. Pertimbangannya adalah bahwa pelatihan hakikatnya juga merupakan sebuah pembelajaran. Oleh karena itu konsep ini bisa diadaptasikan. Model Bintek pelatihan dengan sistem blended dapat mengatasi kelemahan pelatihan tatap muka yang mengharuskan terjadinya pembelajarn di suatu tempat secara bersama-sama untuk semua guru dan keterbatasan waktu untuk datang dan belajar bersama.

Berdasarkan latar belakang masalah yang dipaparkan diatas maka dapat di rumuskan tujuan pelatihan ini adalah: 1) menemukan kebutuhan pelatihan dalam menyusun instrumen ranah sikap; 2) mengenal secara pasti sejauhmana tingkat kompetensi guru - guru SD di lingkungan Gugus Dr. Wahidin Soediro Hoesodo Batang dalam menyusun instrumen penilaian ranah afektif/sikap; dan 3) meningkatkan kompetensi guru SD di lingkungan sanggar PKG Gugus Dr. Wahidin Soediro Hoesodo - Batang dalam menyusun instrumen penilaian ranah afektif. Manfaat PM ini, sesuai 
dengan tujuan tersebut di atas, adalah sebagai sarana untuk meningkatkan kompetensi guru dalam menyususn instrumen penilaian, khususnya ranah afektif. Di samping itu produk dari kegiatan PM ini dapat digunakan sebagai instrumen penilaian alternatif dalam melakukan penilaian di berbagai SD di lingkungan KKG Gugus Dr. Wahidin Soediro Hoesodo, Batang, manfaat lain, sekaligus menyiapkan guru dalam menyongsong dan mendukung pemberlakuaan Kurikulum 13 secara nasional.

\section{METODE}

Ruang lingkup pelatihan dan pendampingan penyusunan instrumen ranah afektif bagi guru-guru SD gugus Dr. Wahidin Soediro Hoesodo - Batang Menggunakan model Blended Learning ini meliputi: Analisis KD dalam Kurikulum 2013 jenjang SD/MI, Hakikat penilaian SD, Hakikat penyusunan instrumen ranah sikap, Rambu-rambu penyusunan skala sikap, Pendampingan Penyusunan instrumen skala sikapMekanisme pendampingan penyusunan instrumen penilaian skala sikap secara online/daring.Mekanisme pendampingan penyusunan instrumen penilaian skala sikap secara online/daring, Pendampingan penyusunan instrumen skala sikap secara online, dan RKTL.

Keinovasian dalam proyek perubahan ini adalah adanya kegiatan bimbingan teknik dengan menggunakan model Blended. Konsep pelatihan (training) menggunakan model blended sebenarnya diadaptasi dari model pembelajaran berbasis blended learning. Blended learning adalah pembelajaran yang menggabungkan dua sistem: yaitu sistem pembelajaran tatap muka yang bersifat klasikal (traditional learning) dan sistem pembelajaran yang menggunakan media computer/e-learning (Bonk \& Graham, 2012). Pembelajaran tatap muka dapat dilakukan dengan model presentasi, diskusi dan kerja kelompok, sementara sistem e-learning dapat berlangsung secara online melalui internet.

Berdasarkan pengertian blended learning tersebut di atas, maka konsep ini dapat diterapkan dalam Bintek pelatihan penulisan dan publikasi karya ilmiah guru SD. Pertimbangannya adalah bahwa pelatihan hakikatnya juga merupakan sebuah pembelajaran. Oleh karena itu konsep ini bisa diadaptasikan. Model Bintek pelatihan dengan sistem blended dapat mengatasi kelemahan pelatihan tatap muka yang mengharuskan terjadinya pembelajarn di suatu tempat secara bersama-sama untuk semua guru dan keterbatasan waktu untuk datang dan belajar bersama.

\section{HASIL DAN PEMBAHASAN}

\section{Pelaksanaan Pelatihan dan Pendampingan Penyusunan Instrumen Skala Sikap}

Sebagaimana diketahui bahwa dalam Kurikulum 2013, ada empat Kompetensi Inti (KI) yang harus dinilai, yaitu KI-1 sikap religius, KI-2 sikap sosial, KI-3 tentang kompetensi pengetahuan dan KI-4 tentang kompetensi ketarampilan. Berkaitan dengan pengalaman melaksanaakan penilaian ke-empat kompetensi ini, para guru SD menyatakan bahwa praktik penilaian kompetensi KI-1 dan KI-2 yang berkaitan dengan ranah afektif masih belum memadai, dibandingkan dengan praktik penilaian untuk KI- 
3 dan KI-4. Para guru belum terlatih menyusun instrumen penilaian ranah afektif. Oleh karena itu upaya meningkatkan kompetensi guru dalam menyusun instrumen ranah afektif/sikap perlu dilakukan. Upaya yang dipandang tepat untuk meningkatkan kompetensi guru ini adalah dengan melakukan pelatihan. Dengan demikian pelatihan penyusunan instrumen penilaian ranah sikap merupakan kebutuhan yang mendesak.

Kegiatan Pelatihan dan pendampingan Penyusunan Instrumen Ranah Afektif bagi Guru-Guru SD Gugus Dr. Wahidin Soediro Hoesodo Batang Menggunakan Model Blended Learning ini dilaksanakamn pada tanggal 13 April 2019 dan 3 Mei 2019 . Kegiatan yang berlangsung dalam 2 kali tatap muka dan dilanjutkan dengan pelatihan dan pendampingan online sampai dengan bulan oktober, dengan durai setara 7 hari kegiatan. Kegiatan tatap muka ini diadakan di Gugus Dr. Wahidin Soediro HoesodoBatang. Peserta pelatihan berjumlah 25 orang guru SD.

\section{Kegiatan tatap muka}

Kegiatan tatap muka pada tanggal 13 April 2019 dan tanggal 3 Mei 2019 menjelaskan tentang bagaimana pelatihan dilakukan. Kegiatan ini dilakukan untuk memberikan pembelakalan bagi para peserta. Pembekalan pertama menyangkut kemampuan peserta untuk menggunakan sarana komputer dan koneksi internet untuk pelatihan. Selanjutnya peserta dikenalkan pada portal pelatihan dengan URL: http://portalbelajarmandiri.net.

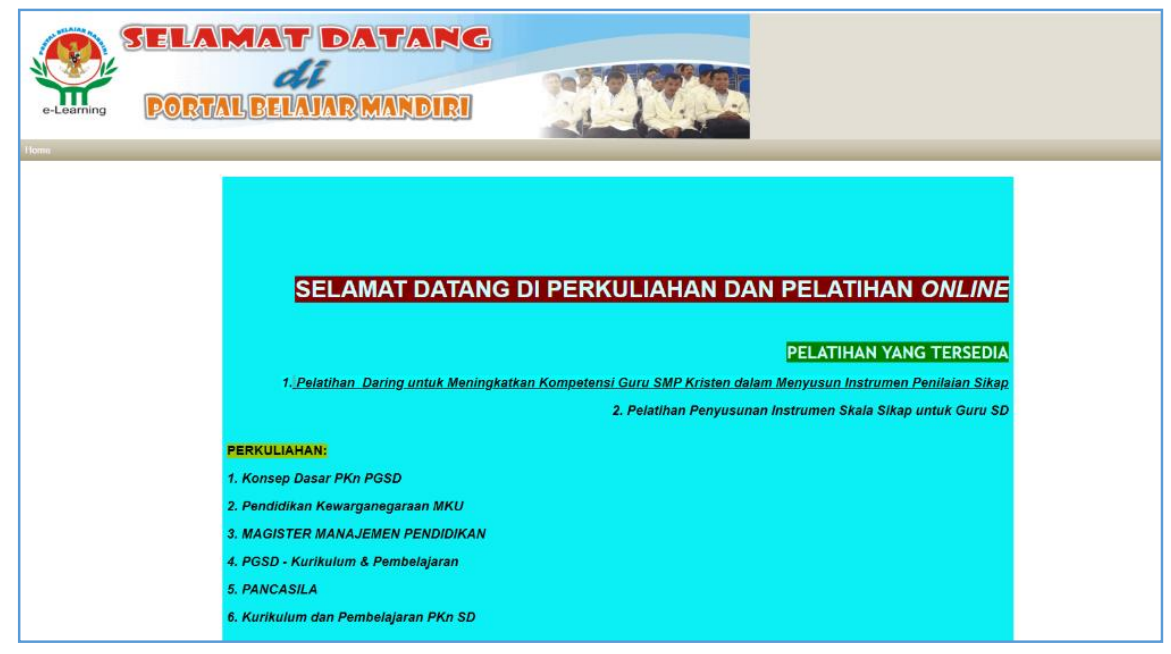

Gambar 2. Halaman muka URL http://portalbelajarmandiri.net

Secara khusus pada tanggal 3 Mei 2019, para peserta diminta membaca dan memahami panduan pelatihan online. Panduan tersebut sepanjang 15 halaman (terdapat di dalam portal belajar). 


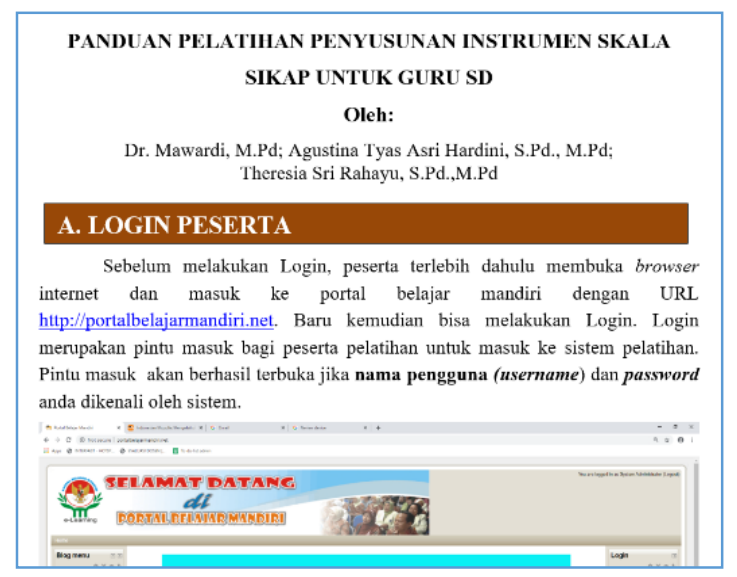

Gambar 3. Panduan pelatihan

Setelah peserta pelatihan memahami bagaimana pelatihan dilakukan dan panduan dicermati, maka langkah berikutnya adalah melakukan kegiatan pelatihan online. Berikut uraian setiap langkahnya.

\section{Kegiatan pelatihan dan Pendampingan online}

1) Langkah 1 : melakukan pretes

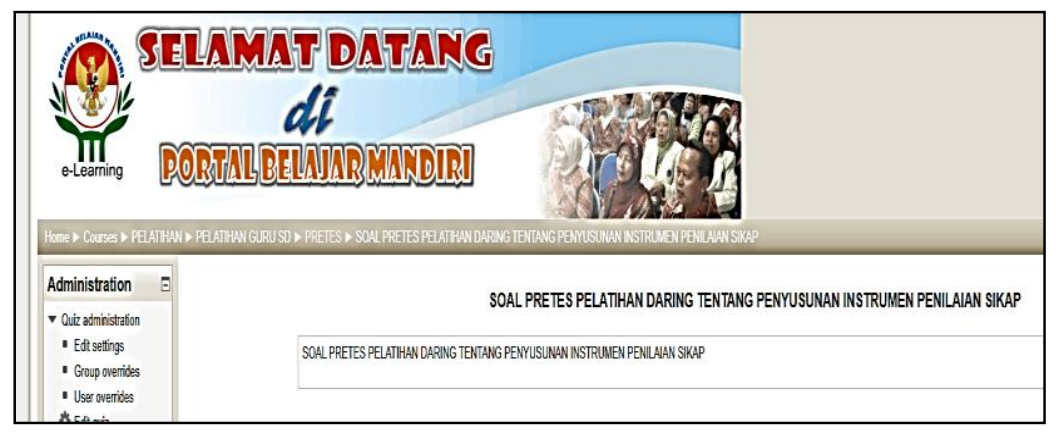

Gambar 4. Halaman pretes

2) Langkah 2:

Membaca materi TOPIK 1. ANALISIS KOMPETENSI DASAR DALAM KURIKULUM SD/MI dan dilanjutkan dengan mengerjakan tugas berkaitan dengan topik tersebut.

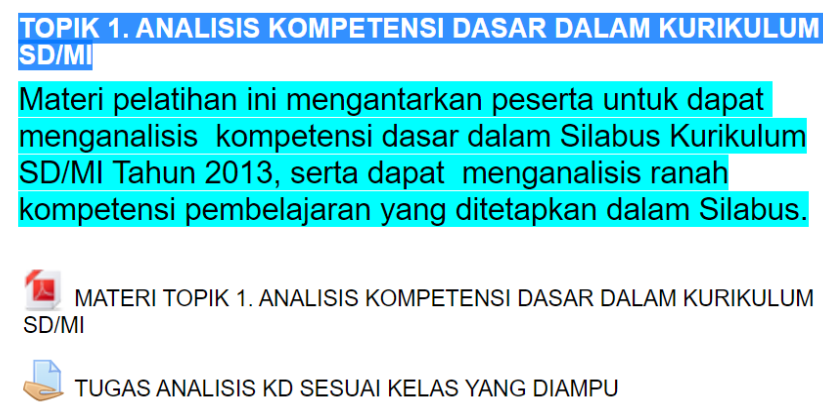

Gambar 5. Topik 1 
3) Selanjutnya membaca materi TOPIK 2. PENGANTAR UMUM PENILAIAN PEMBELAJARAN

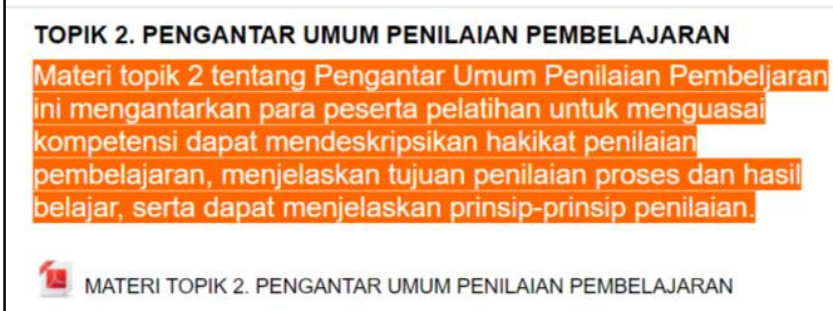

Gambar 6. Topik 2

4) Selanjutnya membaca materi TOPIK 3. HAKIKAT PENILAIAN SIKAP

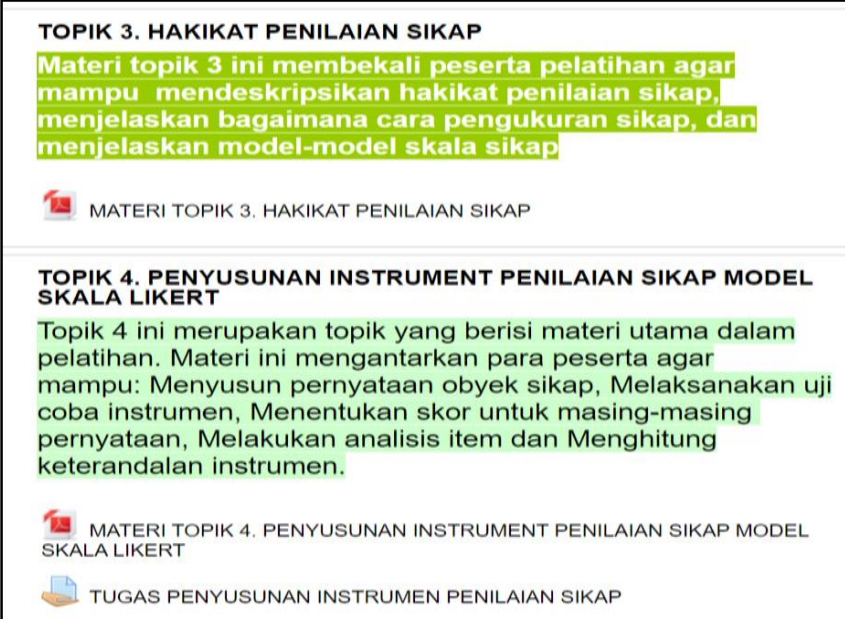

Gambar 7. Topik 3 dan 4

5) Selanjutnya membaca materi TOPIK 4. PENYUSUNAN INSTRUMENT PENILAIAN SIKAP MODEL SKALA LIKERT, dilanjutkan dengan mengerjakan tugas menyusun instrumen penilaian sikap menggunakan model skala sikap model Likert.

6) Langkah ke-3: mengerjakan postes.

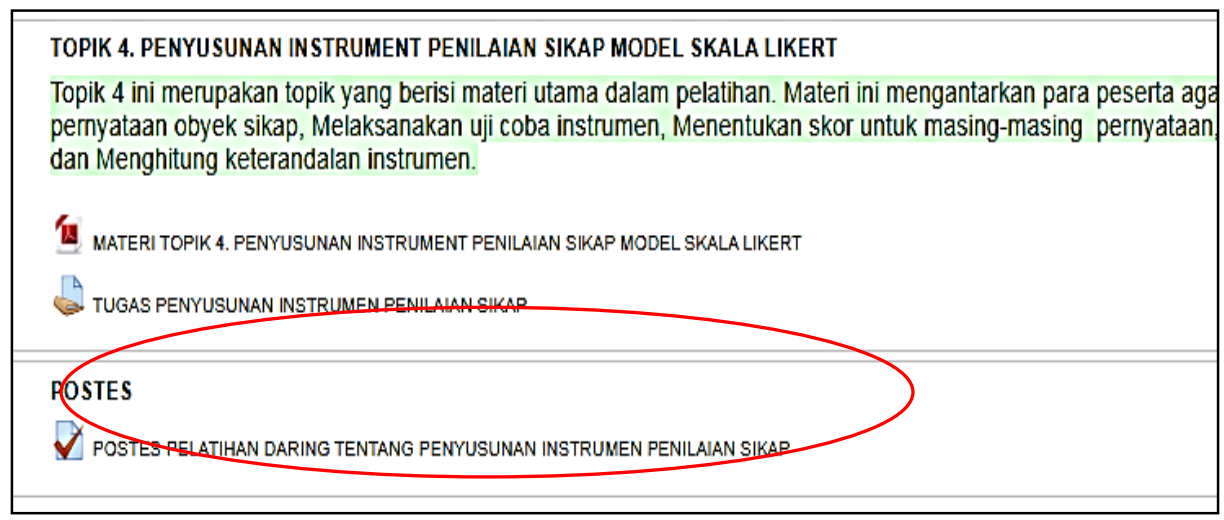

Gambar 8. Postes 


\section{Hasil Pelatihan dan Pendampingan Penyusunan Instrumen Skala Sikap model Likert}

Hasil pelatihan dan pendampingan penyusunan instrumen penilaian ranah sikap ini dideskripsikan berdasarkan dua tujuan PM ini, yaitu mengenal secara pasti sejauhmana tingkat kompetensi guru - guru SD di lingkungan Gugus Dr. Wahidin Soediro Hoesodo - Batang dalam menyusun instrumen penilaian ranah sikap; serta meningkatkan kompetensi guru SD di lingkungan gugus Dr. Wahidin Soediro Hoesodo - Batang dalam menyusun instrumen penilaian sikap.

\section{Tingkat kompetensi guru SD gugus Dr. Wahidin Soediro Hoesodo}

Tingkat kompetensi guru SD dalam mengikuti kegiatan pelatihan didasarkan pada data hasil postes berikut.

Tabel 1. Statistik deskriptif tingkat kompetensi guru SD dalam pelatihan

\begin{tabular}{ll|rr}
\hline & & Pretes & Postes \\
\hline \multirow{2}{*}{$\mathrm{N}$} & Valid & 25 & 25 \\
\cline { 2 - 4 } & Missing & 0 & 0 \\
\hline Mean & 54,00 & 69,76 \\
\hline Standar Deviation & 14,059 & 7,137 \\
\hline Minimum & 23 & 47 \\
\hline Maximum & 72 & 79 \\
\hline
\end{tabular}

Tabel 1 menunjukkan rerata skor pretes dalam pelatihan hanya mencapai 54; sedangkan pada postes mencapai 69,76. Skor minimal pretes 23 dan postes 47; Skor maksimum pretes 72 dan postes 79 . Kenaikan capaian hasil belajar ini cukup berarti, baik dilihat dari reratanya maupun dari capaian skor maksimum yang mencapai 79 .

Tabel 2. Distribusi frekuensi tingkat kompetensi guru SD dalam pelatihan

\begin{tabular}{cccccc}
\hline \multirow{2}{*}{ No } & \multirow{2}{*}{ Interval skor } & \multicolumn{2}{c}{ Pretes } & \multicolumn{2}{c}{ Postes } \\
\cline { 3 - 6 } & & Frekuensi & Persentase & Frekuensi & Persentase \\
\hline 1 & $\geq 80$ & 0 & $0 \%$ & 0 & $0 \%$ \\
2 & $60-79$ & 8 & $32,0 \%$ & 23 & $92,0 \%$ \\
3 & $40-59$ & 14 & $56,0 \%$ & 2 & $8,0 \%$ \\
4 & $20-39$ & 3 & $12,0 \%$ & 0 & $0 \%$ \\
5 & $<20$ & 0 & $0 \%$ & 0 & $0 \%$ \\
\hline & Total & 25 & $100 \%$ & 25 & $100 \%$ \\
\hline
\end{tabular}

\section{Peningkatan kompetensi guru SD dalam menyusun Skala Sikap}

Kemampuan guru SD gugus Dr. Wahidin Soediro Hoesodo dalam menyusun skala sikap telah mencapai mengalami peningkatan. Ditemukan data dari 25 guru SD yang mengikuti pelatihan, 16 dari mereka (68\%) telah mengunggah produk pelatihan berupa instrumen Skala Sikap model Likert. Jika dibandingkan dengan target PM yang ditetapkan sebesar $60 \%$, maka capaian ini telah melampaui target. Peningkatan juga nampak dari capaian kompetensi peserta pelatihan bahwa rerata pretes sebesar 54 dan postes sebesar 69,76 , artinya ada peningkatan sebesar $22,8 \%$. Besaran peningkatan ini cukup signifikan. 
Pembahasan dalam artikel bertujuan untuk: (1) menjawab rumusan masalah dan pertanyaan-pertanyaan penelitian; (2) menunjukkan bagaimana temuan-temuan itu diperoleh; (3) menginterpretasi/menafsirkan temuan-temuan; (4) mengaitkan hasil temuan penelitian dengan struktur pengetahuan yang telah mapan; dan (5) memunculkan teori-teori baru atau modifikasi teori yang telah ada.

\section{SIMPULAN}

Berdasarkan temuan hasil pelatihan seperti telah dideskripsikan di atas, maka dapat disempulkan berikut: 1) pelatihan penyusunan instrumen penilaian ranah sikap merupakan kebutuhan yang mendesak; 2) rerata skor pretes dalam pelatihan hanya mencapai 54; sedangkan pada postes mencapai 69,76. Skor minimal pretes 23 dan postes 47; Skor maksimum pretes 72 dan postes 79 . Kenaikan capaian hasil belajar ini cukup berarti, baik dilihat dari reratanya maupun dari capaian skor maksimum yang mencapai 79 ; 3) Ditemukan data dari 25 guru SD yang mengikuti pelatihan, 16 dari mereka (68\%) telah mengunggah produk pelatihan berupa instrumen Skala Sikap model Likert. Jika dibandingkan dengan target PM yang ditetapkan sebesar $60 \%$, maka capaian ini telah melampaui target.

\section{Ucapan Terima Kasih}

Terimakasih kepada pihak Universitas Kristen Satya Wacana yang telah memberikan dana untuk pengabdian masyarakat ini sehingga bisa berlangsung dan berjalan dengan baik.

\section{REFERENSI}

Balitbang Depdiknas. (2006). Panduan penilaian berbasis kelas. Jakarta: Depdiknas.

Bonk, C. J., \& Graham, C. R. (2012). The handbook of blended learning: Global perspectives, local designs. John Wiley \& Sons.

Mudjiman, H. (2011). Manajemen Pelatihan berbasis Belajar mandiri. Yogyakarta: Pustaka Pelajar

Noe, R. A., Hollenbeck, J. R., Gerhart, B., \& Wright, P. M. (2010). Human Resources Management: Gaining a Competitive Advantage, 1-799. New York: McGraw-Hill.

\section{Copyright and License}

This is an open access article distributed under the terms of the Creative Commons Attribution 4.0 International License, which permits unrestricted use, distribution, and reproduction in any medium, provided the original work is properly cited. (C) 2020 Mawardi, Agustina Tyas Asri Hardini. 